\title{
Deep brain stimulation of pallidal versus subthalamic for patients with Parkinson's disease: a meta-analysis of controlled clinical trials
}

This article was published in the following Dove Press journal:

Neuropsychiatric Disease and Treatment

22 June 2016

Number of times this article has been viewed

Fan $\mathrm{Xu} \mathbf{u}^{\prime}$

Wenbin $\mathrm{Ma}^{2}$

Yongmin Huang'

Zhihai Qiu'

Lei Sun'

'Interdisciplinary Division of Biomedical Engineering, The Hong Kong Polytechnic University, Hung Hom, Hong Kong SAR, People's Republic of China; ${ }^{2}$ Department of Neurology, Binzhou Medical University Hospital, Binzhou, Shandong, People's Republic of China

Correspondence: Lei Sun Interdisciplinary Division of Biomedical Engineering, The Hong Kong Polytechnic University, Hung Hom 999077, Hong Kong SAR, People's Republic of China Tel +852 27667663

Email htsunlei@polyu.edu.hk
Background: Parkinson's disease (PD) is a common neurodegenerative disorder that affects many people every year. Deep brain stimulation (DBS) is an effective nonpharmacological method to treat PD motor symptoms. This meta-analysis was conducted to evaluate the efficacy of subthalamic nucleus (STN)-DBS versus globus pallidus internus (GPi)-DBS in treating advanced PD.

Methods: Controlled clinical trials that compared STN-DBS to GPi-DBS for short-term treatment of PD in adults were researched up to November 2015. The primary outcomes were the Unified Parkinson's Disease Rating Scale Section (UPDRS) III score and the levodopaequivalent dosage (LED) after DBS. The secondary outcomes were the UPDRS II score and the Beck Depression Inventory (BDI) score.

Results: Totally, 13 studies containing 1,148 PD patients were included in this meta-analysis to compare STN-DBS versus GPi-DBS. During the off-medication state, the pooled weighted mean difference (WMD) of UPDRS III and II scores were -2.18 ( $95 \% \mathrm{CI}=-5.11$ to 0.74$)$ and -1.96 (95\% CI $=-3.84$ to -0.08$)$, respectively. During the on-medication state, the pooled WMD of UPDRS III and II scores were $0.15(95 \% \mathrm{CI}=-1.14$ to 1.44$)$ and $1.01(95 \% \mathrm{CI}=0.12$ to 1.89$)$, respectively. After DBS, the pooled WMD of LED and BDI were -254.48 (95\% CI $=-341.66)$ and 2.29 ( $95 \% \mathrm{CI}=0.83$ to 3.75 ), respectively.

Conclusion: These results indicate that during the off-medication state, the STN-DBS might be superior to GPi-DBS in improving the motor function and activities of daily living for PD patients; but during the on-medication state, the opposite result is observed. Meanwhile, the STN-DBS is superior at reducing the LED, whereas the GPi-DBS shows a significantly greater reduction in BDI score after DBS.

Keywords: Parkinson disease, deep brain stimulation, subthalamic nucleus, globus pallidus internus

\section{Introduction}

Parkinson's disease (PD) is the second most common neurodegenerative disorder (after Alzheimer disease) of the central nervous system that mainly affects the motor system. This disease was found to affect approximately 7,000,000 people globally and $1,000,000$ people in USA in $2012 .{ }^{1}$ In 2013, this disease resulted in approximately 100,000 deaths worldwide, up from 44,000 deaths in $1990 .^{2}$ The lack of objective diagnostic tools and effective therapeutic methods are the two major problems for the prevention and treatment of PD. Recently, researchers have been tempted to use metabolomic technologies, which have been widely used to identify novel diseasespecific biomarkers, ${ }^{3-5}$ to develop objective diagnostic testing for PD. As for treatment 
methods, currently, the antiparkinson medication levodopa and dopamine agonists are still the first-line treatment method for PD. These medications could improve the early symptoms of PD, ${ }^{6}$ but they become ineffective and even produce side effects, such as dyskinesias and psychotic symptoms, ${ }^{7}$ as the disease progresses and treatment time is prolonged. The development of these symptoms might be associated with the imbalance between striatopallidal (indirect) pathway and striatonigral (direct) pathway. Many therapeutic methods have been developed to overcome these symptoms, while maintaining adequate levodopa level to produce efficacy. However, to date, the side effects of long-term levodopa treatment are still not fully resolved. ${ }^{8}$ Many PD patients still respond unsatisfactorily to adjustments in pharmacological treatment. ${ }^{9}$ Therefore, many nonpharmacological methods, such as deep brain stimulation (DBS), have been developed and studied to overcome these difficulties.

DBS is a surgical intervention used when the pharmacological therapies are ineffective to control PD motor symptoms. ${ }^{10,11}$ This method was clinically used to treat PD in the late 1990s, and the acceptance of it has increased over the past 20 years. The original assumption of DBS was that the chronic and high-frequency stimulation of brain areas might have comparable efficacy to the surgical ablation of these areas. ${ }^{12}$ For example, stimulating the globus pallidus internus (GPi) or subthalamic nucleus (STN) could replace the traditional pallidotomy to treat PD. ${ }^{13}$ Previous studies reported that DBS could provide remarkable benefits and similar efficacy as levodopa in treating PD. ${ }^{14,15}$ A meta-analysis also reported that with the optimal stimulation parameters, DBS could effectively reduce the motor symptoms of limb rigidity, tremor, akinesia, and bradykinesia. ${ }^{16}$ Additionally, Weaver et al even found that DBS was superior to the best medical therapy in managing motor symptoms and improving quality of life (QoL). ${ }^{17}$ Due to the reversible and the adjustable stimulation parameters used according to the symptoms, DBS is more acceptable for aged patients.

Nowadays, the GPi and STN are the two main brain regions that DBS stimulates to treat $\mathrm{PD}$. Researchers found that both STN-DBS and GPi-DBS could improve the motor function of PD patients. ${ }^{18,19}$ But, a meta-regression showed that combined with levodopa, the GPi-DBS seemed to preserve postural instability and gait disability better than STN-DBS. ${ }^{16}$ However, other studies reported that STN-DBS had a better record compared to GPi-DBS. ${ }^{20,21}$ Actually, it still remains questionable about which one is the optimal therapy. A meta-analysis conducted in April 2013 reported that there was no difference in the therapeutic efficacy between STN-DBS and GPi-DBS in treating PD. ${ }^{22}$ But this conclusion was obtained by only analyzing a pool of five studies. Moreover, some qualified studies were not included in this meta-analysis. In addition, several studies comparing the efficacy of STN-DBS versus GPi-DBS have been published recently. ${ }^{23,24}$ Both studies reported that the STN-DBS group had lower Unified Parkinson's Disease Rating Scale Section (UPDRS) III score than the GPi-DBS group. But Follett et al found that there was a lower UPDRS III score in GPi-DBS group than that in STN-DBS group. ${ }^{25}$ Therefore, an additional meta-analysis and systematic review to aid clinicians in making an optimal treatment strategy for PD patients is urgently needed.

\section{Methods}

\section{Study selection}

First, scientific and medical databases including PubMed, Web of Science, Embase, EB Stephens Company (EBSCO), China Biology Medicine (CBM)-disc, WanFang data, and China National Knowledge Internet (CNKI) were searched for controlled clinical trials that compared the efficacy of STN-DBS versus GPi-DBS in treating PD. The following keywords were used: deep brain stimulation, DBS, pallidal, GPi, subthalamic, STN, Parkinson, and PD. The deadline was set to November 2015, and only the articles written in Chinese and English were considered. Conference summaries were also searched to avoid omitting relevant studies.

\section{Inclusion/exclusion criteria}

We used the following criteria to select the qualified studies to conduct meta-analysis: 1) controlled clinical trials comparing STN-DBS versus GPi-DBS in treating PD; 2) the recruited patients meeting the United Kingdom Parkinson's Disease Society Criteria ${ }^{26}$ and were $>18$ years old; 3 ) the outcomes assessed by levodopa-equivalent dosage (LED) or UPDRS; 4) the outcomes assessed within 1 year postsurgery; and 5) patients not taking any excluded medications, drug, and alcohol. Meanwhile, duplicate studies, case reports, reviews, and studies assessing the long-term ( $>1$ year) efficacy were also excluded.

\section{Outcome measures}

UPDRS is widely used in clinics to assess the motor performance and functional status of PD patients. The higher scores represent more severe PD. The UPDRS I was used to assess mental status, mood, and behavior; the UPDRS II was used to assess the activities of daily living; the UPDRS III was used to assess the motor function; and the UPDRS IV was used to assess the complications caused by therapy. ${ }^{27}$ 
Here, the UPDRS II and III were viewed as the secondary and primary outcome, respectively. Meanwhile, the therapy was considered successful if the dose of medication after treatment was significantly reduced. Therefore, we also selected the LED as the primary outcome. Additionally, the Beck Depression Inventory (BDI) score, which was used to assess the depressive symptoms of PD patients, was also viewed as the secondary outcome.

\section{Data extraction}

Two authors independently used the abovementioned inclusion/exclusion criteria to select studies and then extracted the data. The data from the qualified studies included: 1) the clinical characteristics of patients, such as age, sex ratio, and number; 2) the information of DBS, such as unilateral or bilateral, augmentation, or monotherapy; and 3 ) the primary and secondary outcomes. The data were in the form of mean and standard deviation. If these data could not be directly extracted from the study, much work was done to obtain them, including sending e-mail to the author and researching the associated conference summaries and other studies citing the study in question.

\section{Statistical analysis}

All data were continuous, and the included studies used the consistent scales to assess motor function (UPDRS III) and activities of daily living (UPDRS II). Therefore, weighted mean difference (WMD) was calculated in this study to compare the efficacy of STN-DBS versus GPi-DBS. The 95\% confidence interval (CI) was also calculated. We used the Mantel-Haenszel random-effects model, because this model assumed that the included studies might have the varying true treatment efficacy. ${ }^{28}$ The $\chi^{2}$ test resulting in $P$-values $<0.10$ and $I^{2}$ index $>50 \%$ indicated significant heterogeneity. ${ }^{29}$ All analyses were conducted using RevMan5.0 software and according to the recommendations of the 2009 updated method guidelines. ${ }^{30}$

\section{Results}

\section{Workflow of literature research}

There were 858 potential relevant studies in the primary literature search, and 61 duplicate studies existed. After removing the duplicate studies, 722 studies were further excluded by reading the title and abstract. Then, a total of 62 additional studies were removed by two authors independently reading the full text. Therefore, 13 controlled clinical studies were used for this meta-analysis. ${ }^{23-25,31-40}$ Detailed study procedures are described in Figure 1. Two authors independently completed this work, and any disagreements were dealt with by discussion.

\section{Main characteristics}

These included studies recruited 661 adult PD patients receiving STN-DBS and 487 receiving GPi-DBS. Only one study was from the People's Republic of China. ${ }^{23}$ Almost each study had more men than women, which might suggest that PD was more common in men than women. Only three studies provided data about unilateral STN-DBS versus unilateral GPi-DBS. ${ }^{34,35,39}$ After DBS, motor function was assessed using UPDRS III at 6 months in seven studies, 6-8 months in one study, and 12 months in five studies. Only one study did not provide the data of LED. ${ }^{32}$ All patients continued to use antiparkinson medication; then the assessments were conducted during the standardized on- and offmedication phases. ${ }^{33}$ The detailed information is provided in Tables 1 and 2.

\section{UPDRS III score (off-medication)}

UPDRS III score (off-medication) at the end point was available for eleven studies (Figure 2). The pooled WMD was $-2.18(95 \% \mathrm{CI}=-5.11$ to $0.74 ; Z=1.46 ; P=0.14)$, indicating that STN-DBS did not produce any significant improvement over GPi-DBS in the UPDRS III score (offmedication), although a point estimate favored the use of STN-DBS. Sensitivity analysis was conducted by removing the studies that investigated the efficacy of unilateral DBS. This exclusion resulted in the similar effect-size estimate (adjusted WMD $=-3.23 ; 95 \% \mathrm{CI}=-6.96$ to 0.50 ).

\section{UPDRS III score (on-medication)}

UPDRS III score (on-medication) at the end point was available for eleven studies (Figure 3 ). The pooled WMD was 0.15 (95\% $\mathrm{CI}=-1.14$ to $1.44 ; Z=0.23 ; P=0.82$ ), indicating that the GPi-DBS did not produce any significant improvement over STN-DBS in the UPDRS III score (on-medication), although a point estimate favored the use of GPi-DBS. Sensitivity analysis was conducted by removing the studies that investigated the efficacy of unilateral DBS. This exclusion resulted in the similar effect-size estimate (adjusted WMD $=-0.01$; $95 \% \mathrm{CI}=-1.36$ to 1.33 ).

\section{UPDRS II score (off- and on-medication)}

UPDRS II score (off-medication) at the end point was available for three studies (Figure 4A). The pooled WMD was -1.96 (95\% CI $=-3.84$ to $-0.08 ; Z=2.05 ; P=0.04)$, indicating that STN-DBS yielded a significant improvement over GPi-DBS 


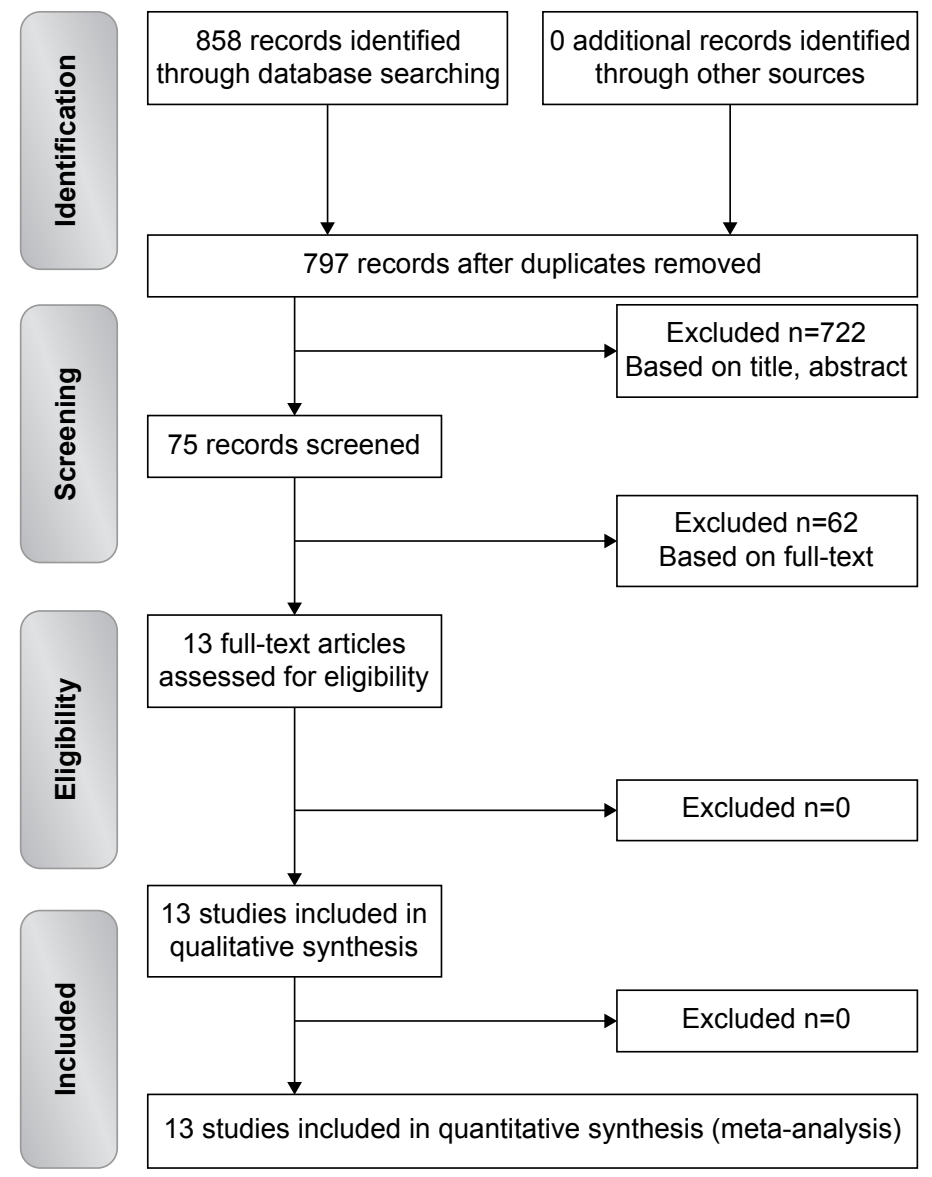

Figure I Workflow of literature research.

in the UPDRS II score (off-medication) 6-12 months after surgery. UPDRS II score (on-medication) at the end point was available for six studies (Figure 4B). The pooled WMD was 1.01 ( $95 \% \mathrm{CI}=0.12$ to $1.89 ; Z=2.22 ; P=0.03$ ), indicating that GPiDBS yielded a significant improvement over STN-DBS in the UPDRS II score (on-medication) 6-12 months after surgery.

\section{LED and BDI score}

LED at the end point was available for 12 studies (Figure 5A). The pooled WMD was $-254.48(95 \% \mathrm{CI}=-341.66$ to $-167.30 ; Z=5.72 ; P<0.00001)$, indicating that the STN-DBS group had larger mean LED reduction between baseline and end point than that of the GPi-DBS group. BDI score

Table I Clinical characteristics of the included patients

\begin{tabular}{|c|c|c|c|c|c|c|c|c|}
\hline \multirow[t]{2}{*}{ Studies } & \multicolumn{4}{|c|}{ Subthalamic nucleus } & \multicolumn{4}{|c|}{ Globus pallidus internus } \\
\hline & $\mathbf{n}$ & $\begin{array}{l}\text { Age, } \\
\text { years }\end{array}$ & $\mathbf{F} / \mathbf{M}$ & $\begin{array}{l}\text { Duration, } \\
\text { years }\end{array}$ & $\mathbf{n}$ & $\begin{array}{l}\text { Age, } \\
\text { years }\end{array}$ & $\mathbf{F} / \mathbf{M}$ & $\begin{array}{l}\text { Duration, } \\
\text { years }\end{array}$ \\
\hline Bai et $\mathrm{al}^{23}$ & 33 & $35-74$ & NA & $3-17$ & 8 & $35-74$ & NA & $3-17$ \\
\hline George et $\mathrm{al}^{24}$ & II & $62.0(5.7)$ & $2 / 9$ & | $3.3(5.0)$ & 10 & $62.8(8.2)$ & $1 / 9$ & I 5.4 (8.7) \\
\hline Follett et $\mathrm{al}^{25}$ & 147 & $61.9(8.7)$ & $31 / 116$ & NA & 152 & $61.8(8.7)$ & $19 / 133$ & NA \\
\hline Burchiel et $\mathrm{al}^{3 \mathrm{I}}$ & 6 & $62.8(12)$ & NA & $13.6(5)$ & 4 & $46.5(\mathrm{II})$ & NA & $10.6(2)$ \\
\hline Anderson et $\mathrm{al}^{32}$ & 12 & $61(9)$ & NA & $15.6(5)$ & II & $54(12)$ & NA & $10.3(2)$ \\
\hline Odekerken et $\mathrm{al}^{33}$ & 63 & $60.9(7.6)$ & $19 / 44$ & $12.0(5.3)$ & 65 & $59.1(7.8)$ & $21 / 44$ & $10.8(4.2)$ \\
\hline Rothlind et $\mathrm{al}^{34}$ & 19 & $61.4(10.1)$ & $4 / 15$ & $12.9(4.3)$ & 23 & $60.2(8.8)$ & $5 / 18$ & I3.3 (6.4) \\
\hline Zahodne et $\mathrm{al}^{35}$ & 20 & $61.3(9.0)$ & $6 / 14$ & $13.6(3.9)$ & 22 & $61.3(5.5)$ & $6 / 16$ & $12.4(3.6)$ \\
\hline Deep-Brain Stimulation for & 96 & $59.0(9.6)$ & $36 / 60$ & $5.6(10.1)$ & 38 & $55.7(9.8)$ & $\mathrm{I} \mid / 27$ & $4.5(9.8)$ \\
\hline \multicolumn{9}{|c|}{ Parkinson's Disease Study Group ${ }^{36}$} \\
\hline Weaver et $\mathrm{al}^{37}$ & 70 & $60.7(8.9)$ & $24 / 56$ & I I. $3(4.7)$ & 89 & $60.4(8.3)$ & $12 / 77$ & II.4 (4.9) \\
\hline Katayama et $\mathrm{al}^{38}$ & II & $27-27$ & NA & NA & 7 & $27-27$ & NA & NA \\
\hline Oyama et $\mathrm{al}^{39}$ & 159 & $61.4(9.0)$ & $29 / 130$ & $1 \mathrm{I} .5(9.2)$ & 43 & $61.9(6.9)$ & $18 / 25$ & I5.5 (8.0) \\
\hline Rocchi et al $^{40}$ & 15 & $61.4(5.5)$ & $4 / 11$ & $11.9(4.8)$ & 14 & $61.1(8.4)$ & $1 / 13$ & $12.9(10.2)$ \\
\hline
\end{tabular}

Note: Data presented as range or mean (standard deviation).

Abbreviations: $F$, female; $M$, male; NA, not available. 
Table 2 Information about the interventions in the included studies

\begin{tabular}{|c|c|c|c|c|}
\hline Studies & $\begin{array}{l}\text { Method (subthalamic nucleus/ } \\
\text { globus pallidus internus) }\end{array}$ & Strategy & Duration & Outcome \\
\hline Bai et $\mathrm{al}^{23}$ & Bilateral/bilateral & Augmentation & $12 \mathrm{mo}$ & UPDRS III/II, LED \\
\hline George et $\mathrm{al}^{24}$ & Bilateral/bilateral & Augmentation & $6 \mathrm{mo}$ & UPDRS III, LED \\
\hline Follett et $\mathrm{al}^{25}$ & Bilateral/bilateral & Augmentation & $6,24 \mathrm{mo}$ & UPDRS III/II, LED, BDI \\
\hline Burchiel et $\mathrm{al}^{3 \mathrm{I}}$ & Bilateral/bilateral & Augmentation & $12 \mathrm{mo}$ & UPDRS III, LED \\
\hline Anderson et $\mathrm{al}^{32}$ & Bilateral/bilateral & Augmentation & $12 \mathrm{mo}$ & UPDRS III/II \\
\hline Odekerken et $\mathrm{al}^{33}$ & Bilateral/bilateral & Augmentation & $12 \mathrm{mo}$ & UPDRS III/II, LED \\
\hline Rothlind et $\mathrm{al}^{34}$ & Unilateral/unilateral & Augmentation & $6 \mathrm{mo}$ & LED, BDI \\
\hline Zahodne et $\mathrm{al}^{35}$ & Unilateral/unilateral & Augmentation & $6 \mathrm{mo}$ & UPDRS III, LED, BDI \\
\hline Deep-Brain Stimulation for & Bilateral/bilateral & Augmentation & $6 \mathrm{mo}$ & UPDRS III/II, LED \\
\hline \multicolumn{5}{|c|}{ Parkinson's Disease Study Group ${ }^{36}$} \\
\hline Weaver et $\mathrm{al}^{37}$ & Bilateral/bilateral & Augmentation & $6,24,36 \mathrm{mo}$ & UPDRS III/II, LED \\
\hline Katayama et $\mathrm{al}^{38}$ & Mixed/mixed & Augmentation & $6-8 \mathrm{mo}$ & UPDRS III, LED \\
\hline Oyama et $\mathrm{al}^{39}$ & Mixed/mixed & Augmentation & $12 \mathrm{mo}$ & UPDRS III, LED \\
\hline Rocchi et al $^{40}$ & Bilateral/bilateral & Augmentation & $6 \mathrm{mo}$ & UPDRS III, LED \\
\hline
\end{tabular}

Abbreviations: BDI, Beck Depression Inventory; LED, levodopa-equivalent dosage; mo, month(s); UPDRS, Unified Parkinson's Disease Rating Scale Section.

at the end point was available for three studies (Figure 5B). The pooled WMD was 2.29 ( $95 \% \mathrm{CI}=0.83$ to $3.75 ; Z=3.08$; $P=0.002$ ), indicating that GPi-DBS yielded a greater reduction over STN-DBS in the BDI score 6-12 months after surgery.

\section{Discussion}

This meta-analysis included 13 controlled clinical trials to compare the efficacy of STN-DBS (661 patients) with GPiDBS (487 patients) in the treatment of advanced PD. We found that during the off-medication state, the STN-DBS had nonsignificantly and significantly better efficacy over GPi-DBS in improving the motor function (UPDRS III score: $\mathrm{WMD}=-2.18 ; 95 \% \mathrm{CI}=-5.11$ to 0.74$)$ and activities of daily living (UPDRS II score: WMD $=-1.96$; 95\% $\mathrm{CI}=-3.84$ to -0.08 ) for $\mathrm{PD}$ patients, respectively; but during the on-medication state, GPi-DBS had nonsignificantly and significantly better efficacy over STN-DBS in improving the motor function (UPDRS III score: WMD $=0.15 ; 95 \%$ $\mathrm{CI}=-1.14$ to 1.44 ) and activities of daily living (UPDRS II score: $\mathrm{WMD}=1.01 ; 95 \% \mathrm{CI}=0.12-1.89)$ for PD patients, respectively. Meanwhile, we found that STN-DBS could reduce the postoperative medication levels to significantly lower than that achieved with GPi-DBS (WMD $=-254.48$; $95 \% \mathrm{CI}=-341.66$ to -167.30 ), but GPi-DBS showed a significantly greater reduction in depression score $(\mathrm{WMD}=2.29$; 95\% CI $=0.83-3.75$ ). However, these conclusions should be interpreted with caution owing to the limited number of PD patients.

PD has many symptoms, including the classic parkinsonian triad, other motor signs associated with nondopaminergic transmission, and nonmotor symptoms. ${ }^{41}$ The motor function control is the main goal of $\mathrm{PD}$ treatment. A previous meta-analysis found that both STN-DBS and GPi-DBS could improve motor function. ${ }^{42}$ Another meta-analysis that only included five studies reported a similar efficacy of STN-DBS and GPi-DBS. ${ }^{22}$ However, our meta-analysis found that compared to GPi-DBS, STN-DBS was associated with a better improvement in off-medication state motor symptoms and activities of daily living. But compared to STN-DBS, GPi-DBS was associated with a better improvement in onmedication state motor symptoms and activities of daily living. Our results were consistent with the previous study by Odekerken et al, ${ }^{33}$ in which a relative large number of PD patients was recruited.

The surgery was considered successful if the postoperative medication level was significantly reduced. Here, we found that LED after DBS decreased significantly more in patients receiving STN-DBS than in those receiving GPiDBS on average. The previous meta-analysis also reported similar results. ${ }^{22}$ This difference might be an important consideration for patients who experienced adverse effects of medications. ${ }^{42}$ But one thing should be noted. Previous studies also reported that the reduced medication level made patients suffer more complications ${ }^{41}$ or made some symptoms, such as dyskinesias or tremors, more apparent. ${ }^{43-45}$ Therefore, whether the medication level decrease following DBS resulted from its therapeutic efficacy still remains to be analyzed. In clinical practice, the clinicians should reduce the medication level carefully.

Nonmotor symptoms, such as depression, cognitive impairment, psychological functioning, and anxiety, could even predate motor symptoms of PD. ${ }^{46}$ These symptoms often influenced the patients' QoL, even more than the motor dysfunction sometimes. ${ }^{47}$ Among them, the most important determinant of QoL was depression, which was reported by $35 \%$ of PD patients. ${ }^{48}$ Therefore, it was important to consider these symptoms during motor symptoms 

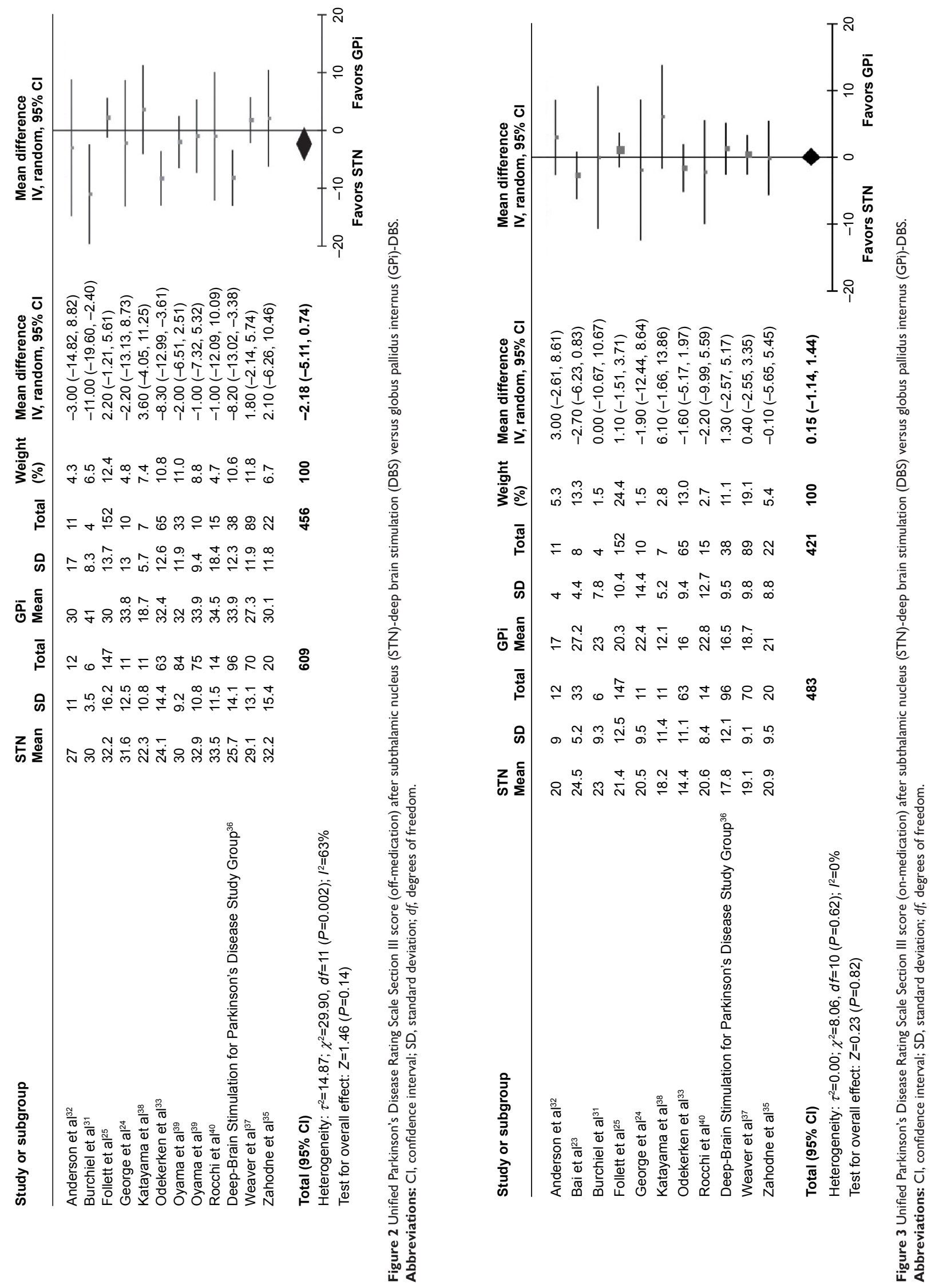


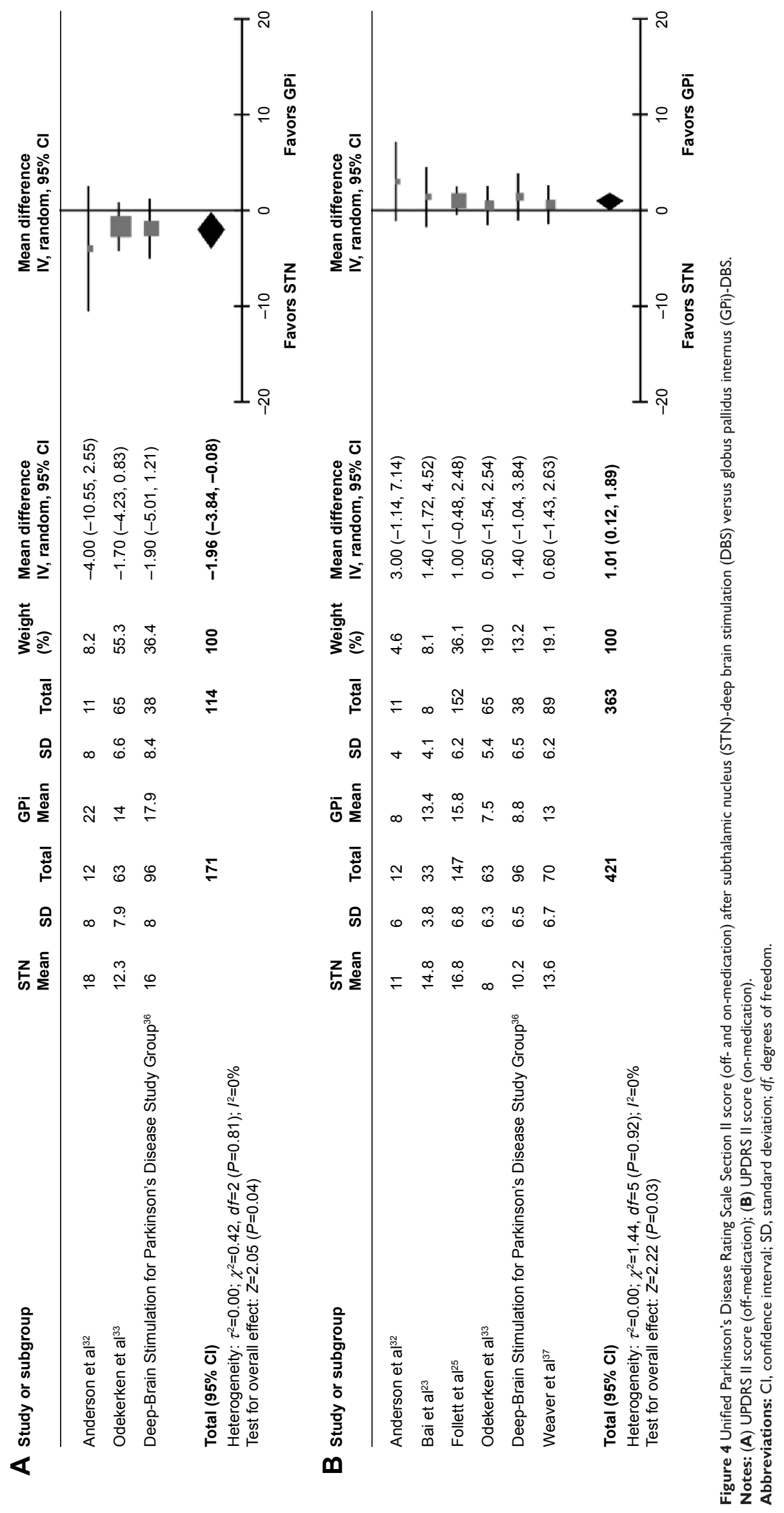




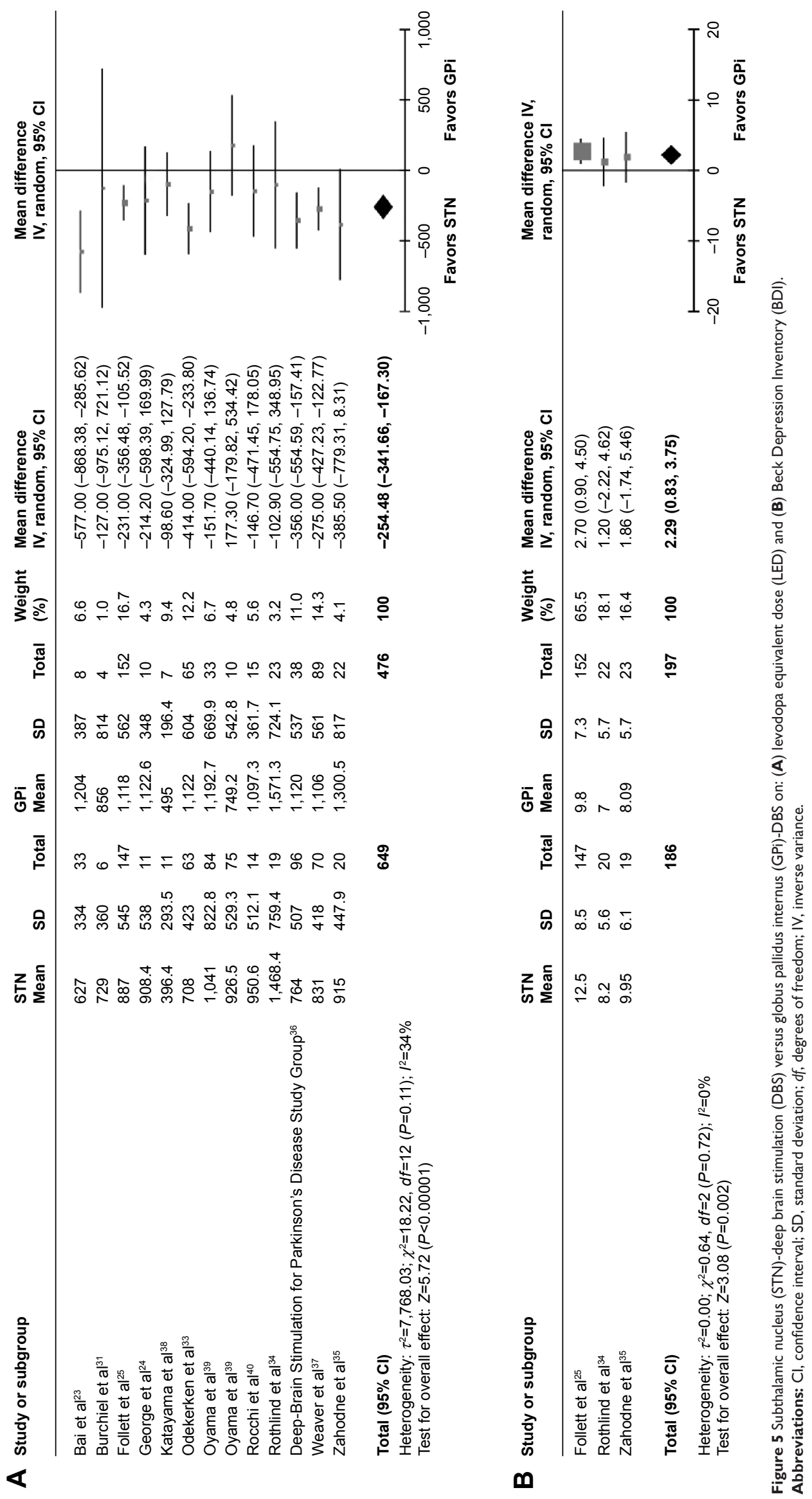


treatment. Recently, DBS has been viewed as an effective treatment for depression. ${ }^{49} \mathrm{~A}$ study found that both unilateral STN-DBS and GPi-DBS could improve the QoL of PD patients. ${ }^{35}$ But, a clinical trial reported that the mood function of PD patients (based on BDI score) was not significantly improved after STN-DBS. ${ }^{50}$ Meanwhile, another study even found that the level of depression of PD patients worsened after STN-DBS, but showed slight improvement after GPiDBS. ${ }^{25}$ In this work, we found that GPi-DBS might be more beneficial in treating depression than STN-DBS. Therefore, GPi-DBS might be more applicable in treating PD patients with depression.

There were several potential limitations. First, the included number of PD patients was relatively small. Second, only the short-term efficacy of DBS in treating PD was assessed; so, whether our conclusion was appropriate for long-term treatment was unclear. Third, only one study was from the People's Republic of China, ${ }^{23}$ which might create bias. Fourth, one study contained smaller number of patients than the other studies, ${ }^{31}$ which might also create bias.

\section{Conclusion}

This meta-analysis indicated that during the off-medication state, STN-DBS might be superior to GPi-DBS in improving the motor function and activities of daily living for PD patients; but during the on-medication state, the opposite result was observed. Meanwhile, LED after DBS was much lower in the STN-DBS group than in the GPi-DBS group, but GPi-DBS showed a significantly greater reduction in BDI score.

\section{Acknowledgment}

This work was supported by The Hong Kong Polytechnic University through grants (1-YW0Q and 1-ZVGK) and National Natural Science Foundation of China (NSFC 61372026).

\section{Disclosure}

The authors report no conflicts of interest in this work.

\section{References}

1. Yao SC, Hart AD, Terzella MJ. An evidence-based osteopathic approach to Parkinson disease. Osteopath Fam Physician. 2013;5(3):96-101.

2. Naghavi M, Wang H, Lozano R, et al. Global, regional, and national age-sex specific all-cause and cause-specific mortality for 240 causes of death, 1990-2013: a systematic analysis for the Global Burden of Disease Study 2013. Lancet. 2015;385(9963):117-171.

3. Chen J, Zhou C, Liu Z, et al. Divergent urinary metabolic phenotypes between major depressive disorder and bipolar disorder identified by a combined GC-MS and NMR spectroscopic metabonomic approach. J Proteome Res. 2015;14(8):3382-3389.
4. Lam CW, Law CY. Untargeted mass spectrometry-based metabolomic profiling of pleural effusions: fatty acids as novel cancer biomarkers for malignant pleural effusions. J Proteome Res. 2014;13(9): 4040-4046.

5. Chen JJ, Huang H, Zhao L, et al. Sex-specific urinary biomarkers for diagnosing bipolar disorder. PLoS One. 2014;9(12):e115221.

6. Bonuccelli U. Comparing dopamine agonists in Parkinson's disease. Curr Opin Neurol. 2003;16(Suppl 1):S13-S19.

7. Cieslak M, Komoszynski M, Wojtczak A. Adenosine A(2A) receptors in Parkinson's disease treatment. Purinergic Signal. 2008;4:305-312.

8. Frucht S, Greene PE. An algorithm (decision tree) for the management of Parkinson's disease (2001): treatment guidelines. Neurology. 2002; 58(1):156-157.

9. Vidailhet M. Movement disorders in 2010: Parkinson disease-symptoms and treatments. Nat Rev Neurol. 2011;7(2):70-72.

10. Williams A, Gill S, Varma T, et al. Deep brain stimulation plus best medical therapy versus best medical therapy alone for advanced Parkinson's disease (PD SURG trial): a randomised, open-label trial. Lancet Neurol. 2010;9(6):581-591.

11. Worth PF. How to treat Parkinson's disease in 2013. Clin Med.2013;13(1): 93-96.

12. Benabid AL, Pollak P, Gervason C, et al. Long-term suppression of tremor by chronic stimulation of the ventral intermediate thalamic nucleus. Lancet. 1991;337:403-406.

13. Benabid AL. Deep brain stimulation for Parkinson's disease. Curr Opin Neurobiol. 2003;13(6):696-706.

14. Deuschl G, Schade-Brittinger C, Krack P, et al. A randomized trial of deep-brain stimulation for Parkinson's disease. $N$ Engl J Med. 2006;355(9):896-908.

15. Rodriguez-Oroz MC, Obeso JA, Lang AE, Houeto JL, Pollak P, Rehncrona S. Bilateral deep brain stimulation in Parkinson's disease: a multicentre study with 4 years follow-up. Brain. 2005;128: 2240-2249.

16. George RJS, Nutt JG, Burchiel KJ, et al. A meta-regression of the long-term effects of deep brain stimulation on balance and gait in PD. Neurology. 2010;75(14):1292-1299.

17. Weaver FM, Follett K, Stern M, et al. Bilateral deep brain stimulation vs best medical therapy for patients with advanced Parkinson disease: a randomized controlled trial. JAMA. 2009;301(1):63-73.

18. Nutt JG, Rufener SL, Carter JH, et al. Interactions between deep brain stimulation and levodopa in Parkinson's disease. Neurology. 2001;57(10): $1835 \mathrm{e} 42$.

19. Burdick AP, Foote KD, Wu S, et al. Do patient's get angrier following STN, GPi, and thalamic deep brain stimulation. Neuroimage. 2011;54: S227-S232.

20. Krack P, Batir A, Van Blercom N, et al. Five-year follow-up of bilateral stimulation of the subthalamic nucleus in advanced Parkinson's disease. N Engl J Med. 2003;349(20):1925-1934.

21. Woods SP, Rippeth JD, Conover E, et al. Statistical power of studies examining the cognitive effects of subthalamic nucleus deep brain stimulation in Parkinson's disease. Clin Neuropsychol. 2006;20(1): 27-38.

22. Liu Y, Li W, Tan C, et al. Meta-analysis comparing deep brain stimulation of the globus pallidus and subthalamic nucleus to treat advanced Parkinson disease: a review. J Neurosurg. 2014;121(3):709-718.

23. Bai MM, Zhong H, Li J. Comparison the efficacy of deep brain stimulation with different target points on patients of parkinsons disease. J Yanan Univ. 2015;13(2):18-23.

24. St George RJ, Carlson-Kuhta P, King LA, et al. Compensatory stepping in Parkinson's disease is still a problem after deep brain stimulation randomized to STN or GPi. J Neurophysiol. 2015;114(3):1417-1423.

25. Follett KA, Weaver FM, Stern M, et al. Pallidal versus subthalamic deep-brain stimulation for Parkinson's disease. $N$ Engl J Med. 2010; 362(22):2077-2091.

26. Hughes AJ, Ben-Shlomo Y, Daniel SE, Lees AJ. What features improve the accuracy of clinical diagnosis in Parkinson's disease: a clinicopathologic study. Neurology. 1992;42:1142-1146. 
27. Goetz CG, Poewe W, Rascol O; Movement Disorder Society Task Force on Rating Scales for Parkinson's Disease. The Unified Parkinson's Disease Rating Scale (UPDRS): status and recommendations. Mov Disord. 2003; 18:738-750.

28. Riley RD, Higgins JP, Deeks JJ. Interpretation of random effects meta-analyses. Br Med J. 2011;342:d549.

29. Higgins JP, Thompson SG, Deeks JJ, Altman DG. Measuring inconsistency in meta-analyses. Br Med J. 2003;327:557.

30. Furlan AD, Pennick V, Bombardier C, et al. 2009 updated method guidelines for systematic reviews in the Cochrane Back Review Group. Spine. 2009;34(18):1929-1941.

31. Burchiel KJ, Anderson VC, Favre J, et al. Comparison of pallidal and subthalamic nucleus deep brain stimulation for advanced Parkinson's disease: results of a randomized, blinded pilot study. Neurosurgery. 1999;45(6):1375.

32. Anderson VC, Burchiel KJ, Hogarth P, et al. Pallidal vs subthalamic nucleus deep brain stimulation in Parkinson disease. Arch Neurol. 2005; 62(4):554-560.

33. Odekerken VJJ, van Laar T, Staal MJ, et al. Subthalamic nucleus versus globus pallidus bilateral deep brain stimulation for advanced Parkinson's disease (NSTAPS study): a randomised controlled trial. Lancet Neurol. 2013;12(1):37-44.

34. Rothlind JC, Cockshott RW, Starr PA, et al. Neuropsychological performance following staged bilateral pallidal or subthalamic nucleus deep brain stimulation for Parkinson's disease. J Int Neuropsychol Soc. 2007;13(01):68-79.

35. Zahodne LB, Okun MS, Foote KD, et al. Greater improvement in QoL following unilateral deep brain stimulation surgery in the globus pallidus as compared to the subthalamic nucleus. J Neurol. 2009; 256(8):1321-1329.

36. Deep-Brain Stimulation for Parkinson's Disease Study Group. Deep-brain stimulation of the subthalamic nucleus or the pars interna of the globus pallidus in Parkinson's disease. N Engl J Med. 2001;345(13):956-963.

37. Weaver FM, Follett KA, Stern M, et al. Randomized trial of deep brain stimulation for Parkinson disease thirty-six-month outcomes. Neurology. 2012;79(1):55-65.

38. Katayama Y, Kasai M, Oshima H, et al. Double blinded evaluation of the effects of pallidal and subthalamic nucleus stimulation on daytime activity in advanced Parkinson's disease. Parkinsonism Relat D. 2001; 7(1):35-40.
39. Oyama G, Foote KD, Jacobson CE, et al. GPi and STN deep brain stimulation can suppress dyskinesia in Parkinson's disease. Parkinsonism Relat D. 2012;18(7):814-818.

40. Rocchi L, Carlson-Kuhta P, Chiari L, Burchiel KJ, Hogarth P, Horak FB. Effects of deep brain stimulation in the subthalamic nucleus or globus pallidus internus on step initiation in Parkinson disease: laboratory investigation. J Neurosurg. 2012;117(6):1141-1149.

41. Fasano A, Daniele A, Albanese A. Treatment of motor and non-motor features of Parkinson's disease with deep brain stimulation. Lancet Neurol. 2012;11:429-442.

42. Weaver F, Follett K, Hur K, Ippolito D, Stern M. Deep brain stimulation in Parkinson disease: a meta-analysis of patient outcomes. J Neurosurg. 2005;103:956-967.

43. Ferrer I, López-Gonzalez I, Carmona M, Dalfó E, Pujol A, Martínez A. Neurochemistry and the non-motor aspects of PD. Neurobiol Dis. 2012;46:508-526.

44. Meissner WG. When does Parkinson's disease begin? From prodromal disease to motor signs. Rev Neurol. 2012;168:809-814.

45. Tarsy D, Scollins L, Corapi K, O'Herron S, Apetauerova D, Norregaard T. Progression of Parkinson's disease following thalamic deep brain stimulation for tremor. Stereotact Funct Neurosurg. 2005;83: 222-227.

46. Doorn KJ, Lucassen PJ, Boddeke HW, et al. Emerging roles of microglial activation and non-motor symptoms in Parkinson's disease. Prog Neurobiol. 2012;98:222-238.

47. Global Parkinson's Disease Survey Steering Committee. Factors impacting on quality of life in Parkinson's disease: results from an international survey. Mov Disord. 2002;17(1):60.

48. Reijnders JS, Ehrt U, Weber WE, Aarsland D, Leentjens AF. A systematic review of prevalence studies of depression in Parkinson's disease. Mov Disord. 2008;23:183-189.

49. Serra-Blasco M, de Vita S, Rodríguez MR, et al. Cognitive functioning after deep brain stimulation in subcallosal cingulate gyrus for treatmentresistant depression: an exploratory study. Psychiatry Res. 2015; 225(3):341-346.

50. Heo JH, Lee KM, Paek SH, et al. The effects of bilateral subthalamic nucleus deep brain stimulation (STN DBS) on cognition in Parkinson disease. J Neurol Sci. 2008;273(1):19-24.
Neuropsychiatric Disease and Treatment

\section{Publish your work in this journal}

Neuropsychiatric Disease and Treatment is an international, peerreviewed journal of clinical therapeutics and pharmacology focusing on concise rapid reporting of clinical or pre-clinical studies on a range of neuropsychiatric and neurological disorders. This journal is indexed on PubMed Central, the 'PsycINFO' database and CAS,

\section{Dovepress}

and is the official journal of The International Neuropsychiatric Association (INA). The manuscript management system is completely online and includes a very quick and fair peer-review system, which is all easy to use. Visit http://www.dovepress.com/testimonials.php to read real quotes from published authors. 